\title{
Design and Fabrication of Thermoplastic Moulds for Manufacturing CFRP Composite Impeller Blades
}

\author{
SORIN DRAGHICI ${ }^{1}$, IONUT SEBASTIAN VINTILA ${ }^{2 *}$, RADU MIHALACHE ${ }^{2}$, \\ HORIA ALEXANDRU PETRESCU ${ }^{1}$, CATALIN STELIAN TUTA ${ }^{\mathbf{3}}$, ANTON HADAR ${ }^{\mathbf{1 , 4 , 5}}$ \\ ${ }^{1}$ University Politehnica of Bucharest, Department of Strength of Materials, 313 Splaiul Independenţei, 060032, Bucharest, \\ Romania \\ ${ }^{2}$ National Research and Development Institute for Gas Turbines COMOTI, 220 D Iuliu Maniu Bd, District 6, Bucharest \\ Romania \\ ${ }^{3}$ Horia Hulubei National Institute for R\&D in Physics and Nuclear Engineering, 30 Reactorului St., Bucharest - Magurele, \\ Romania \\ ${ }^{4}$ Academy of Romanian Scientists, 125 Calea Victoriei, 010071, Bucharest, Romania \\ 5 Technical Sciences Academy of Romania, 26 Dacia Blvd, Bucharest, 010413, Romania
}

\begin{abstract}
The main objective of this study was to investigate thermoplastic materials design and fabrication processes for manufacturing composite impeller blades. Polyurethane (Necuron) and ABS (3D printed) thermoplastics were chosen due to their good mechanical properties, tooling applications, easy manufacturing and lifetime. For both thermoplastics, workability and hardness tests were performed, as well as microstructural and mechanical characterization evaluating their physical and mechanical properties. A 1:2.5 scale mould was designed and milled from Necuron N651 and N1001 and used for manufacturing of 1:2.5 scale composite impeller blades. Also, 1:1 scale ABS mould components were $3 D$ printed and used to manufacture full scale composite impeller blades. All composite impeller presented good surface quality and tolerances with respect to CAD design, thus answering to requirements related to composite processing
\end{abstract}

Keywords: polyurethane material, composite materials, impeller blade, centrifugal rotor

\section{Introduction}

It has been proven that technology breakthroughs happened due to significant material progress and researches. This class of composite materials is characterized by the marriage of quite diverse individual components that work together to produce capabilities exceeds those of their separate elements and their unique properties make them the materials for major technological advances. fibre reinforced polymeric matrix composite (CFRP) have enormous potential in the construction, transport, aerospace and energy sectors because of their durability, light weight and ability to be manufactured in complex shapes. Initial applications of composite materials to aircraft structures were in secondary structures such as fairings, small doors and control surfaces. As the technology matured, the use of composite materials for primary structures such as wings and fuselages has increased. Their applications in industries like aerospace are not only related to high thrust-to-weight ratio, but also to their corrosion and fatigue resistance. Moreover, these material present high stiffness to weight ratio optimization, thermal and environment resistance for high performances and fuel efficiency [1]. These composite materials are usually used in the form of prepregs, for ease of manufacturing, labour cost and time. Prepregs can be manufactured according to beneficiary requirements, varying in resin and fibre type and volume. Figure 1, presents a summary of prepreg technology and its main advantages.

Most of the major types of renewable energy cycles require a piece of turbomachinery. The concept of continuous fibre woven impeller initially originated for development of an axial compressor that utilized these novel impellers for compressing water vapour as a refrigerant. Research aims to expand their application across other sectors of energy as shown in figure 2 [2]. Manufacturing a composite impeller blade is a complex task, offering several advantages. Starting from the design and

*email: sebastian.vintila@comoti.ro 
geometry optimisation (aero-elastic studies) with respect to the manufacturing process represents the first step in the development cycle.

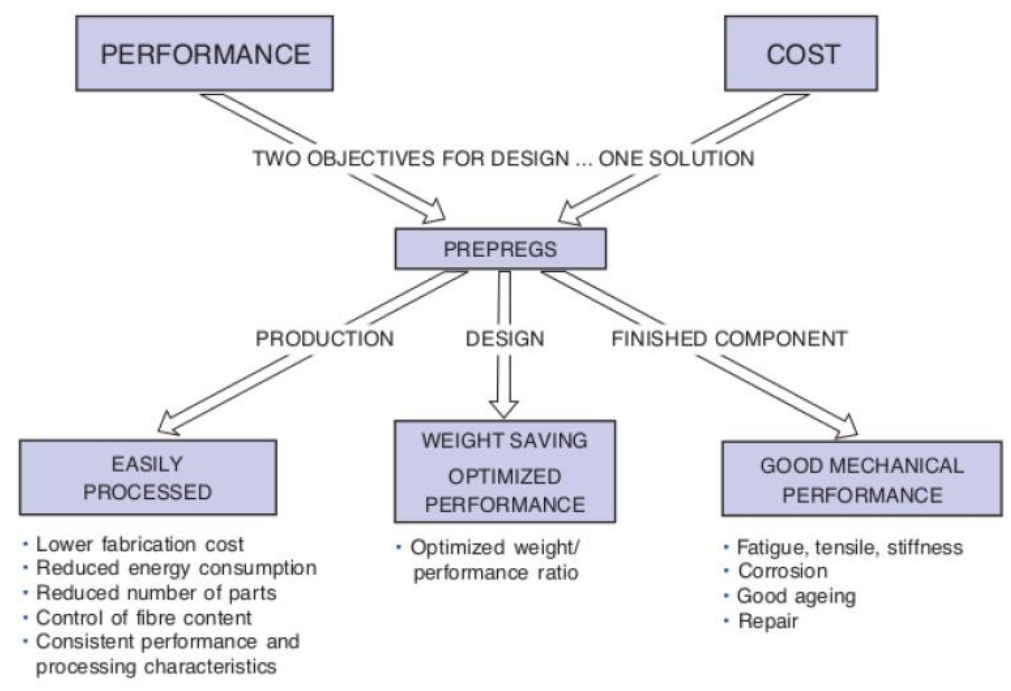

Figure 1. Polymer composite materials properties

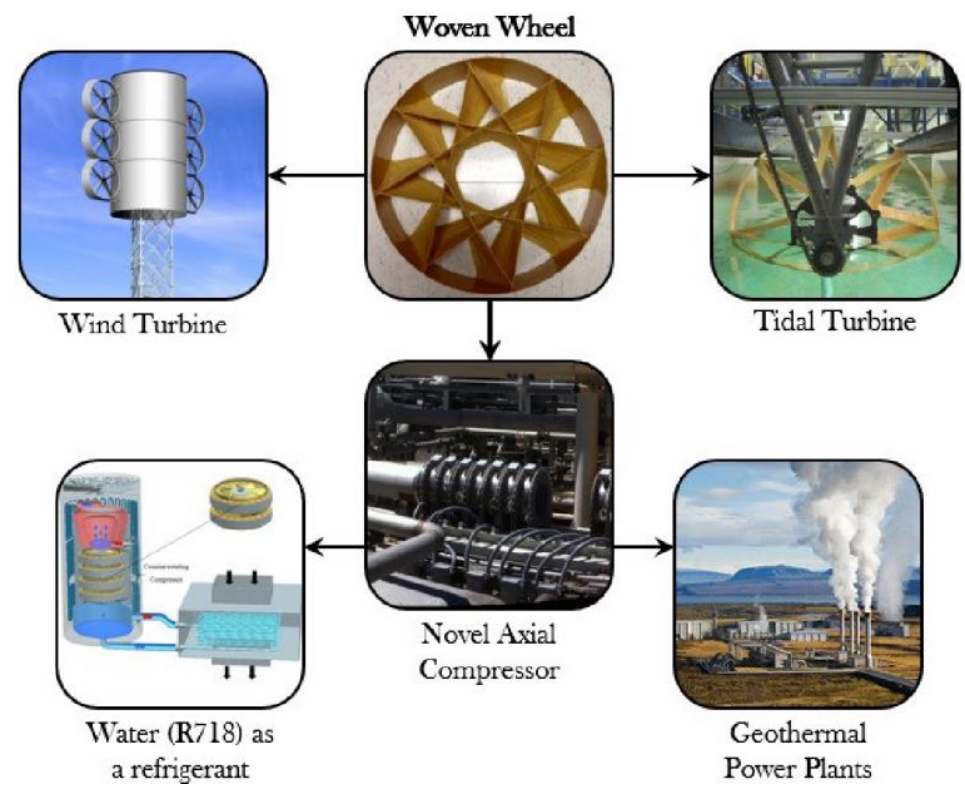

Figure 2. Woven impeller application areas [2]

In the recent years metallic classic materials has been replaced by polymeric materials when modelling, tooling applications, fixtures and jigs are targeted, due to their good mechanical properties, easy manufacturing and lifetime. Polymeric materials like polyurethanes can be both thermoplastic and thermoset, reinforced or not, and can be manufactured through traditional manufacturing methods including extrusion, injection, thermoforming (for thermoplastics) and lay-up, compression moulding and casting (for thermosets). A great application of these reinforced polyurethanes is in moulding tools. Necuron materials [3] are typically thermoplastics made from filled polyurethane and they exhibit very high dimensional stability, low density, high compression strength, good machining, high stiffness, wear resistance making it suitable for different applications: insulators, copy models, rollers, housing parts, clock-gearing, plain bearings, gear wheels, moulding tools, [4, 5]. The mechanical properties are remarkably aligned to the requirements which guarantee constant quality. Researchers have expressed an ongoing interest regarding the mechanical behaviour of different types of polymers through some important studies that use various loading conditions, tensile, compression or more 
complex tests $[6,7]$, bending tests of polyurethane foams [6]. With the increasing applications of these materials, a good knowledge of their workability, chemical, structural, physical and mechanical behaviour is important, mostly because many data sheets lack information about material properties.

\section{Materials and methods}

Starting from the metallic reference rotor design presented in Figure 3, a new and optimised geometry has been made (Figure 4) that will generate at least $50 \%$ weight reduction of the rotary assembly and better performances related to fuel consumption and pollutant emission reductions.
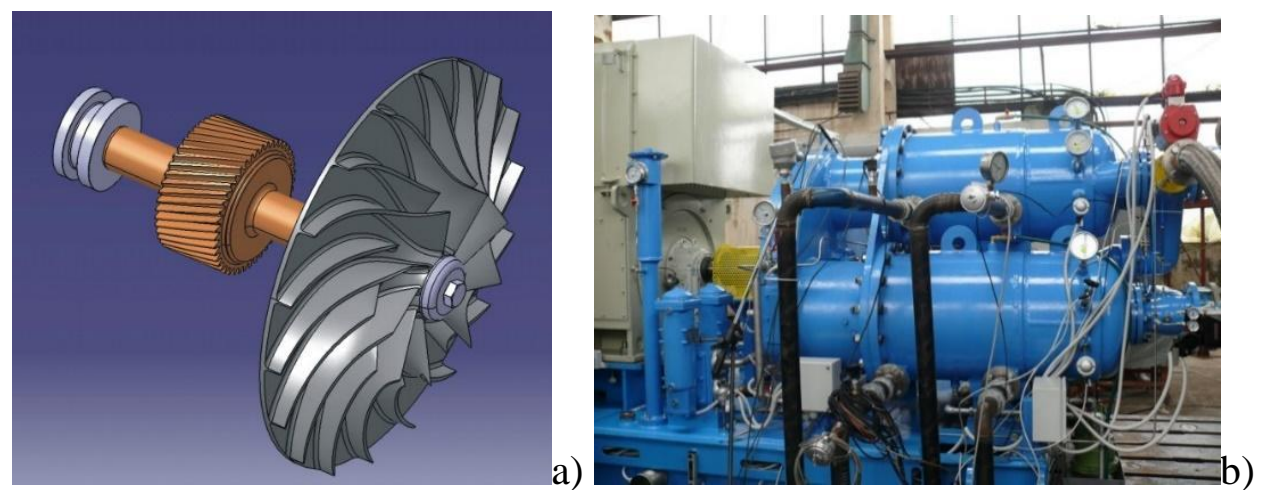

Figure 3. a) Metallic rotor reference as part of

b) Centrifugal air compressor assembly
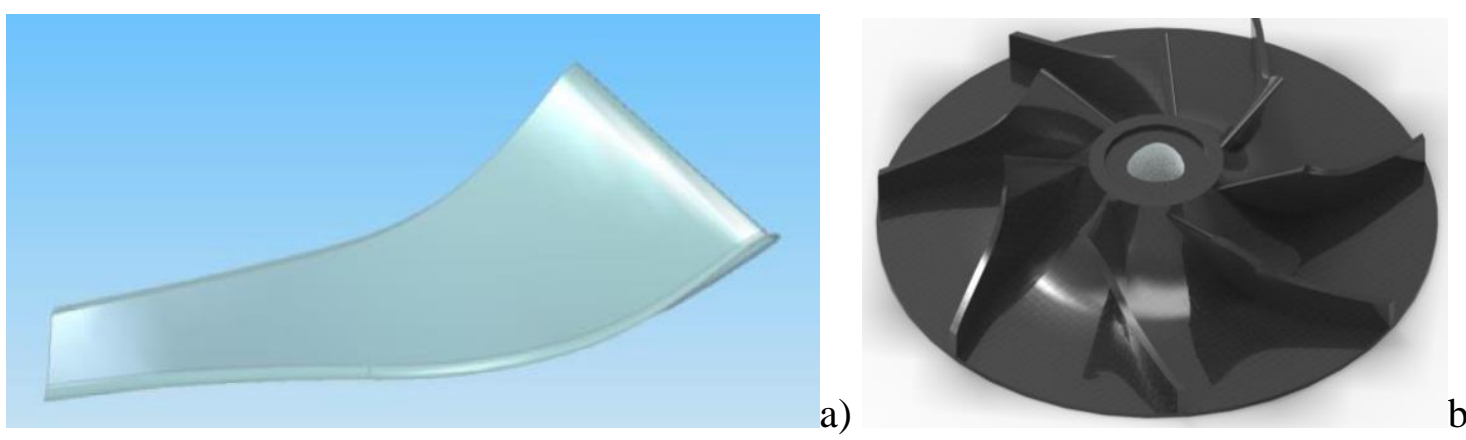

Figure 4. CAD model of a) optimised compressor rotor impeller blade and b) CFRP compressor rotor

The equation 1 and 2 sets the base formula for the centrifugal forces calculations, in the present case a first iteration of calculus takes into account a volume element (i.e. $\Delta \mathrm{V}$ is $2 \times 10^{4} \mathrm{~mm}^{3}, \rho$ is taken for the woven High Strength Carbon Epoxy composite as $1.47 \mathrm{~g} / \mathrm{cm}^{3}$, the acceleration $\omega$ is taken at $17 \times 103 \mathrm{rot} / \mathrm{min}$. and the radius $\mathrm{R}$ is $121,48 \mathrm{~mm}$ ), the centrifugal forces acting on the composite materials structure taken into account within the first iteration is around $11,3 \mathrm{kN}$.

$$
\begin{aligned}
& F_{c}=R \times \omega^{2} \times \rho \times \Delta V,(N) \\
& \omega=2 \times \pi \times n,(\mathrm{rad} / \mathrm{sec})
\end{aligned}
$$

\subsection{Materials, sample preparation and testing methodology}

The experimental program on three commercial polymer materials Necuron 651, 702, and 1001 [8, $9,10]$, consisted in investigating their workability, finding the optimum milling regime, performing roughness measurements, hardness, mechanical tests and structural investigations using scanning electron microscopy SEM equipped with EDAx system. Selection of materials for the 1:2.5 scaled mould of a centrifugal rotor impeller was done based on a set of requirements imposed by the centrifugal compressor rotor/impellers advance composites materials processing and cure stages. The 
mould material has to answer to following requests: low CTE (coefficient of thermal expansion) in order to avoid thermal stress concentrations do to CTE mismatch between mould and processed composite materials, good machining, quality surface, good dimensional stability up to high temperatures (i.e. $140^{\circ} \mathrm{C}$ ) used during composite materials processing.

\subsection{Workability}

Different mechanical processes were used like milling, drilling and polishing. The milling of the mould was realized using a DMU Deckel Maho CNC machine testing several regimes. Following milling and polishing operations, roughness was measured using an electronic roughness tester, Marsurf PS1.

\subsection{Hardness tests}

Hardness of plastics is difficult to establish and compare because when using indenters there is an elastic recovery effect. Rockwell and Shore hardness are typical for plastic materials. Shore hardness tests exclude any elastic recovery effect. Within the present study ShoreD, Rockwell hardness tests were performed on the three materials under study. Shore hardness tests were performed according to ASTM D2240 to determine the relative hardness of materials under study (being used for soft materials, usually plastic or rubber) by penetration with a spring loaded needle-like indenter. Shore D scale was used with loading force of $4536 \mathrm{~g}$. Rockwell hardness tests were performed on EMCO Test M4C025G3M harness equipment according to ASTM D 785, the indentors for the Rockwell test included a diamond cone penetrator having an included angle of $120^{\circ}$ with a spherical tip having a radius of $0.2 \mathrm{~mm}$. The specimen was loaded by a minor load, followed by a major load applied for 15 seconds and then again by same minor load, and then the hardness was read off the dial. Rockwell HR$\mathrm{M}$ and HR-45N scales were used, being commonly used with plastics.

\subsection{Microstructural Analysis}

SEM investigations were conducted on all three Necuron samples. The samples subjected to SEM were first cut into smaller size $(10 \times 10$ x $10 \mathrm{~mm})$ with MetaCut M250Manual Cutoff Machine. After sizing the samples to an appropriate size in order to fit the microscope chamber and coated with gold $100 \AA$ film thickness to be electrically conductive using a cladding machine Emitech SC7620 mini sputter coater. This was realized to prevent the charge-up on the specimen surface and to increase secondary electron emission. SEM investigations at $30 \mathrm{kV}$ voltage, using a spot of 3.5 in both secondary and backscattered electrons, were conducted on a FEI Inspect F50 SEM having a $1 \mathrm{~nm}$ resolution, equipped with Energy Dispersive X-ray system

\subsection{Mechanical characterization}

A short mechanical test campaign was performed for both flexural and compressive strength determination. A number of 5 specimens were tested for each material. All tests were carried out using and $250 \mathrm{kN}$ Instron 8802 hydraulic testing machine, at room temperature in accordance with ISO 178:2010 "Determination of Flexural Properties" and respectively ASTM D695 "Standard Test Method for Compressive Properties of Rigid Plastics".

\subsection{Design and manufacturing of 1:2.5 scale impeller blade mould}

The components of the 1:2.5 scale impeller blade mould were first realized by CAD modelling using SolidEdge 2019 software. Following design assessment, N 651 and 1001 were used in manufacturing of a mould for an impeller blade mould scale 1:2.5. Different mechanical processes were used like milling, drilling and polishing. The milling of the mould was realized using a DMU Deckel Maho CNC milling machine. 


\section{Results and discussions}

\subsection{Workability: optimum milling regime and roughness measurement}

Several milling regimes were tested on N 651 block on four regions (grooves of $8 \mathrm{~mm}$ wide and $0.2 \mathrm{~mm}$ depth). The milling regimes and a picture of grooves are presented in Table 1 below. Following milling and polishing operations on four groove, roughness of the N 651 was measured. In Table 1are presented the roughness of each groove. The optimum roughness was obtained after milling with 4000 rpm speed and 0.01 lead.

Table 1. Milling regimes and roughness on N651

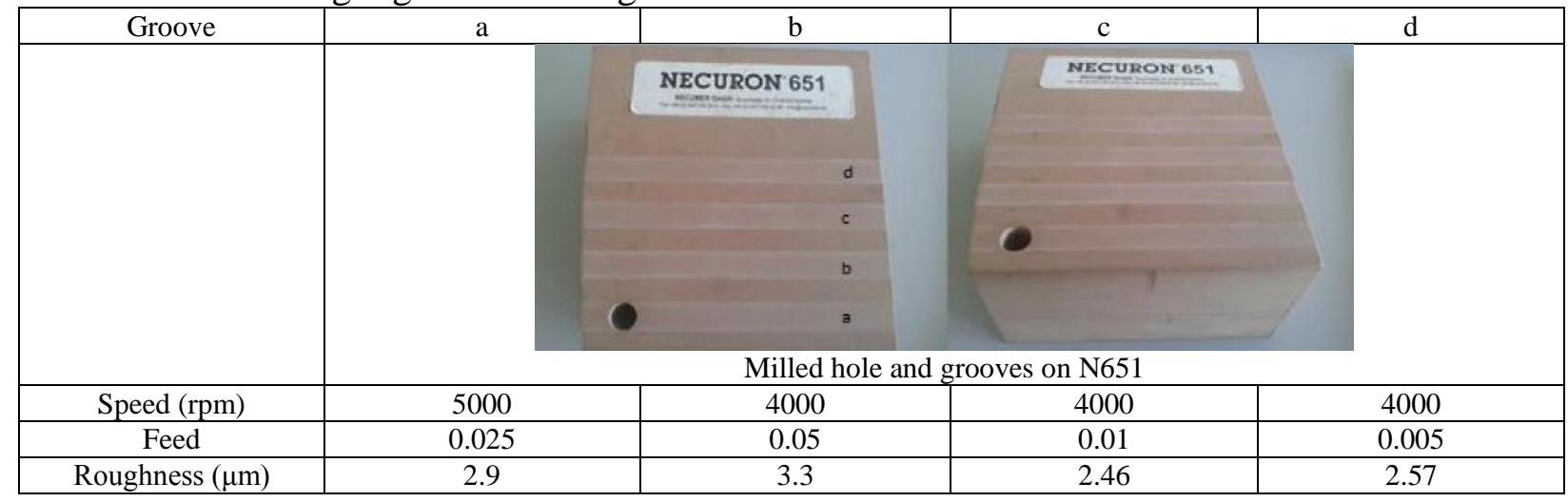

\subsection{Hardness tests}

Before starting the harness test campaign a Brinell test was performed using a steel ball of $5 \mathrm{~mm}$ applying a force of $62.5 \mathrm{kgf}$. Measuring the diameters of the prints using a microscope it was observed that $\mathrm{N} 651$ presents the highest diameter of $4.3 \mathrm{~mm}$ (mean of five measurements), N702 $3.5 \mathrm{~mm}$ and N1001 $2.5 \mathrm{~mm}$. The first indication is that the harder material seems to be N1001.

Table 2. Hardness values of Necuron tested materials

\begin{tabular}{|c|c|c|c|}
\hline \multicolumn{4}{|c|}{ Macro Hardness } \\
\hline $\begin{array}{l}\text { Material: } \\
\text { Necuron }\end{array}$ & $\begin{array}{l}\text { Rockwell HR-4N } \\
\text { Minor Load: } 3 \mathrm{kgf} \\
\text { Major Load: } 45 \mathrm{kgf}\end{array}$ & $\begin{array}{l}\text { Rockwell HR-M } \\
\text { Minor Load: } 10 \mathrm{kgf} \\
\text { Major Load: } 100 \mathrm{kgf}\end{array}$ & $\frac{\text { Shore D }}{4536 \mathrm{~g} \text {. }}$ \\
\hline & \multicolumn{3}{|l|}{ ASTM D 785} \\
\hline N651 & 56.1 & 49 & 68 \\
\hline N702 & 60.8 & 57 & 74 \\
\hline N1001 & 67.8 & 60 & 83 \\
\hline
\end{tabular}

The hardness tests results are summarized in Table 2 above. The values obtained for harness confirmed the first observations performed using Brinell ball indentations, N1001 exhibits the highest hardness from all three analyzed Necuron materials. Nevertheless, the harnesses measured were scattered and the reported values from Table 3 are means of five measurements for each sample material and each testing condition. The raison these scattered measurements is related to pore inhomogeneous distribution in all materials, along with parameters related to casting conditions process with respect to curing effectiveness, depth of cure. The results obtained were correlated with materials morphology showing a clear correlation between the hardness and the porous internal microstructure of materials processed through casting. The inhomogeneous distribution of pores and their size which varies from one material to another leaded to different results in local hardness. The highest hardness of N1001 is explained by the pore lower size and closer distribution as shown by SEM analysis, when compared with N651 and 702 materials. Likewise, the density which is $0.66 \mathrm{~g} / \mathrm{cm}^{3}$ for N651 compared to $702\left(0.78 \mathrm{~g} / \mathrm{cm}^{3}\right)$ and respectively $1001\left(1.19 \mathrm{~g} / \mathrm{cm}^{3}\right)$. 


\subsection{Microstructural analysis}

SEM microstructural analyses were performed at different magnifications, using both secondary and the electron backscatter diffraction (EBSD) technique. A first observation was their high porosity, as the SEM images at magnification 1000x shows (Figure 5). All materials exhibit an average size of the pores from $40-50$ on N1001 and 40 to $80 \mu \mathrm{m}$ on both N651 and N702, and the resin morphology grains presents a typical amorphous structure with sharp edges. Energy Dispersive X-ray analysis results of resin on three materials are typical for polyurethane and polyurethane epoxy blends (figure $6)$.
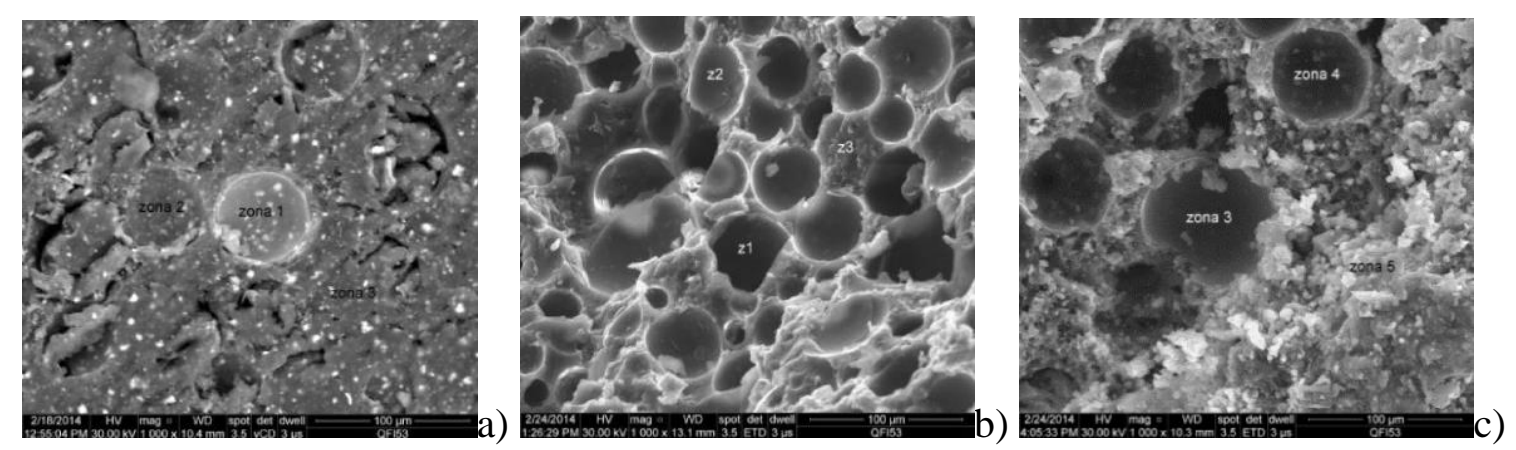

Figure 5. Resin morphology on three analyses materials and areas for EDAX analysis a) N651,

b) N702 and c) N1001
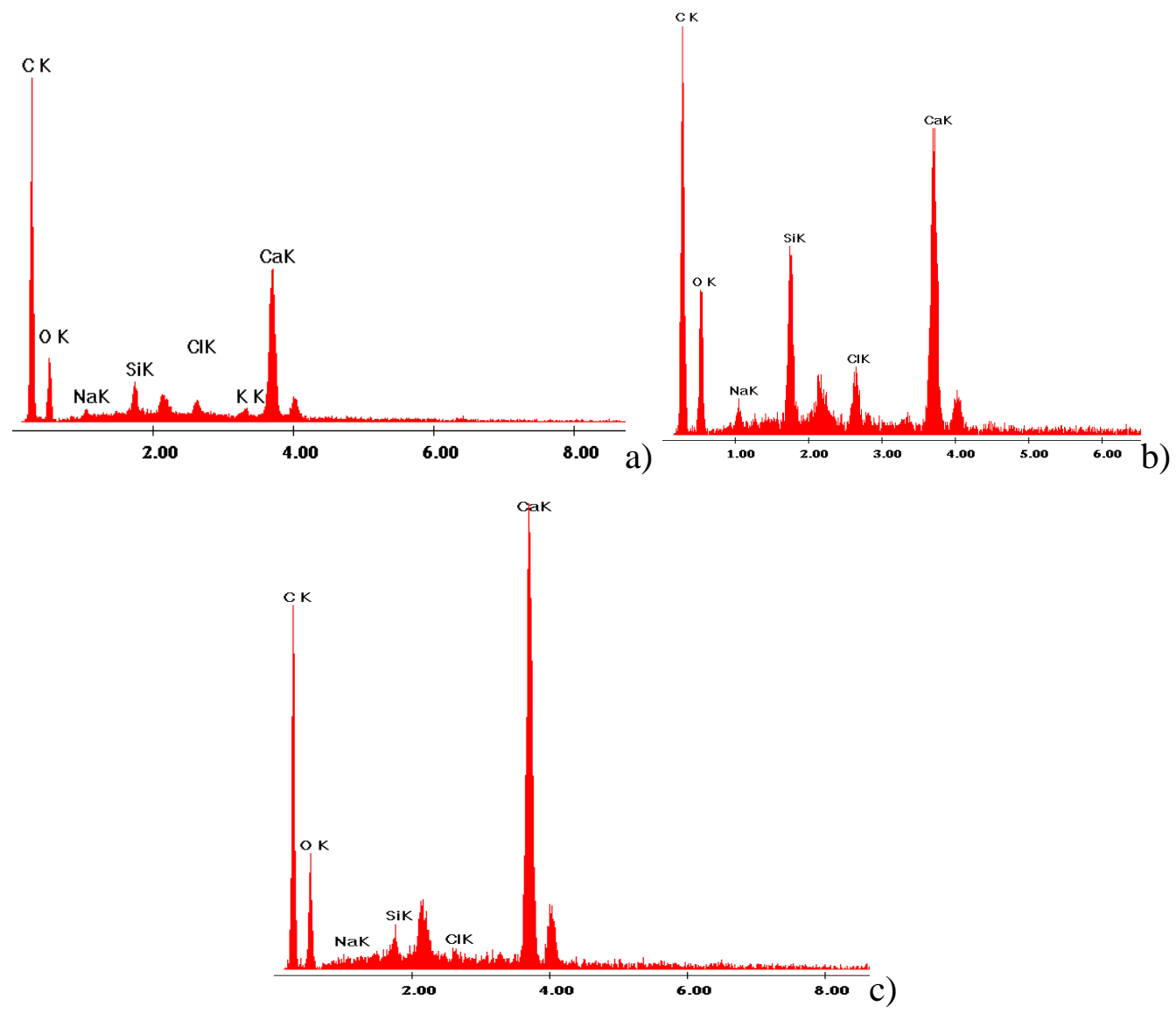

Figure 6. SEM-EDX spectra of a) N651 b) N702; c) N1001

\subsection{Mechanical characterization}

Five samples of each Necuron material were tested in three-point bending and compression regimes and the results are presented as a mean value in table 3. The N1001 presents the highest values, whereas the N702 presents satisfying performances. Nevertheless, when manufacturing a 1:1 
scale mould the best balance must be found between materials properties: CTE, thermal resistance, dimensional stability, mechanical strength, lifetime (reuse, number of manufacturing cycles) and price.

Table 3. Results of mechanical tests

\begin{tabular}{|c|c|c|}
\hline & \multicolumn{2}{|c|}{ Mechanical Properties } \\
\hline Necuron Type & $\begin{array}{c}\text { Flexural Strength } \\
{\left[\mathrm{N} / \mathrm{mm}^{2}\right]}\end{array}$ & $\begin{array}{c}\text { Compressive strength } \\
{\left[\mathrm{N} / \mathrm{mm}^{2}\right]}\end{array}$ \\
\hline 651 & 30 & 26 \\
\hline 702 & 28 & 32 \\
\hline 1001 & 75 & 70 \\
\hline
\end{tabular}

\subsection{Design and manufacturing of $1: 2.5$ scale impeller blade mold}

For the technological mould scale 1:2.5, N651 and 1001 materials were chosen, assuring a CTE of around $50 \times 10^{-6} \mathrm{~K}^{-1}$ and a thermal resistance of $70^{\circ} \mathrm{C}$. Prior to manufacturing the mould, an impeller blade mould (scale 1:2.5) was designed and manufactured. Dimensions of the two blocks were $100 \mathrm{x}$ $97.5 \times 50 \mathrm{~mm}$ for N 651 and $100 \times 110 \times 50 \mathrm{~mm}$ for N 1001. Due to the small scale and geometry complexity, the mould has been made out of three individual components (figure 7). The black coloured face represents the part where the composite material will be placed, forming after polymerization, the composite impeller.
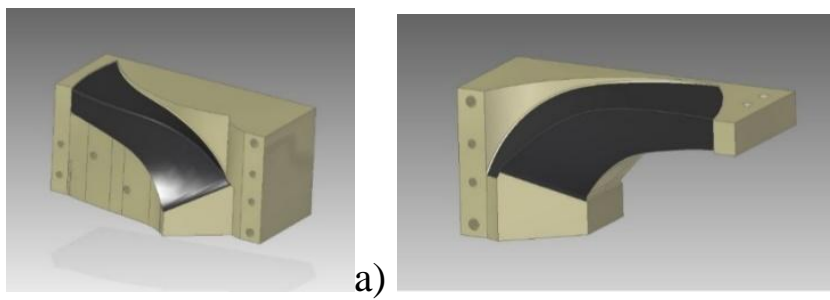

a)

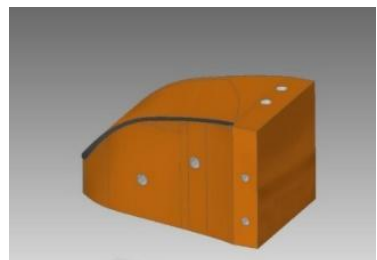

b)

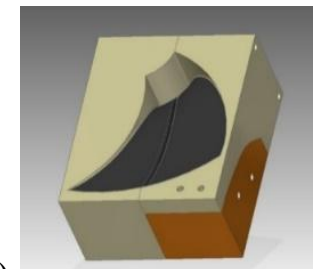

d)

Figure 7. Mould components for the blade a) pressure side, b) suction side, c) blade flow path and d) Mould Assembly (Brown-N 651; Light brown-N 1001)

Starting from CAD design, components were manufactured using a milling machine. To keep the components in place, 8 pins $(\varnothing 3.2 \mathrm{~mm}$ and $9 \mathrm{~mm}$ length) were manufactured out of aluminium. The mechanical processing of Necuron and the final mould is shown below (fig. 8). Milling regimes are presented in table 4. After mould manufacturing finishing operations were conducted and roughness was measured using the same equipment as in previous measurements. N651 presented a $4.9 \mu \mathrm{m}$ roughness while N1010 $3.2 \mu \mathrm{m}$.
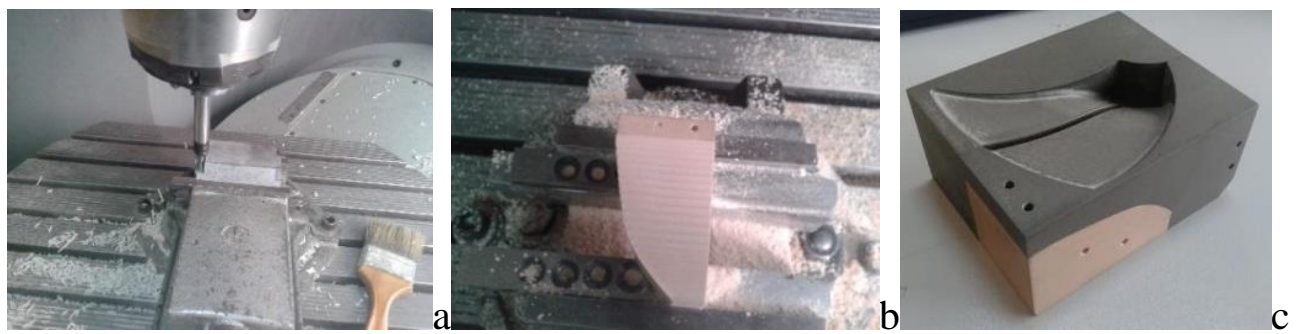

Figure 8. Machining of a) N1001; b) N651; c) final Necuron mould (scale 1:2.5)

Table 4. Milling regimes for 1:2.5 scale Necuron mould manufacturing

\begin{tabular}{|c|c|c|c|}
\hline \multicolumn{2}{|c|}{ Cotter milling } & \multicolumn{2}{c|}{ Planar milling } \\
\hline Speed $[\mathrm{rpm}]$ & 4000 & Speed & 1200 \\
\hline Mill $[\mathrm{mm}]$ & 2.5 & Cutter & 80 \\
\hline Feed rate $[\mathrm{mm} / \mathrm{min}]$ & $200-300$ & Feed rate $[\mathrm{mm} / \mathrm{min}]$ & $200-300$ \\
\hline
\end{tabular}




\subsection{Manufacturing of $1: 2.5$ scale impeller blade}

Necuron V7 was applied to the Necuron mould to create a glossy surface and to lower the mould roughness. The gelcoat was applied several times according to the data sheet to obtain the desired characteristics. HexPly M49/42\%/200T2X2/CHS prepreg was used to manufacture the scaled impeller blade. Six plies of M49 were placed on the mould to obtain the final blade wall thickness of $1.5 \mathrm{~mm}$. The mould assembly was vacuumed bagged and introduced in an oven at $100^{\circ} \mathrm{C}$ for 2 hours to cure the composite. Figure 9 presents the manufactured composite impeller blades.

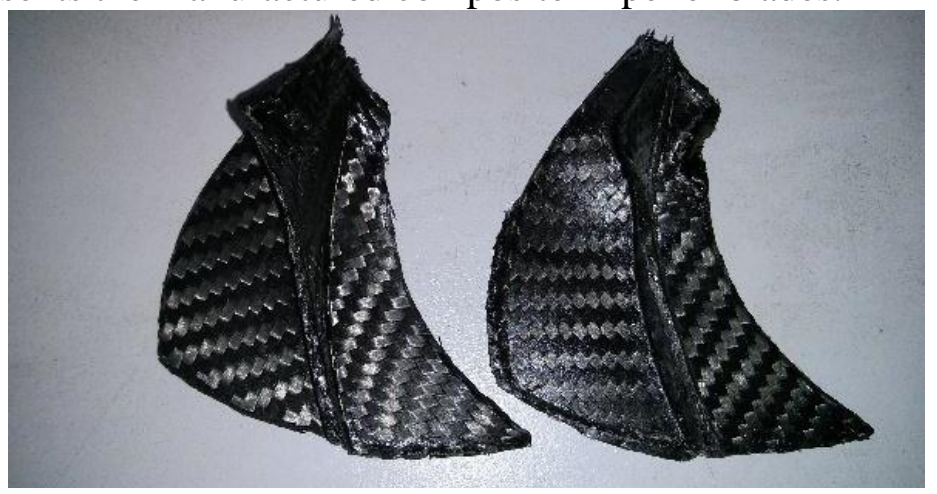

Figure 9. Composite impeller blades, 1:2.5 scale

In addition, thermoplastic ABS parts were 3D printed using Dimension Elite printer to fabricate a 1:1 scale mould, presented in figure 10. Due to printed technique, each part has a very rough surface. Thus, each ABS part was polished using grinding paper until the surface was smooth. Mould parts were degreased to ease the removal of composite part after curing. The same M49 prepreg material has been used for manufacturing the 1:1 scale composite impeller blade, the difference being in the curing temperature. As the ABS material has a maximum use temperature of $87^{\circ} \mathrm{C}$, the curing temperature was set to $82^{\circ} \mathrm{C}$, for a period of 5 hours. The manufactured composite impeller blades present smooth surfaces on the side in contact with the mould. Images of full scale composite impeller blades are presented in figure 11.
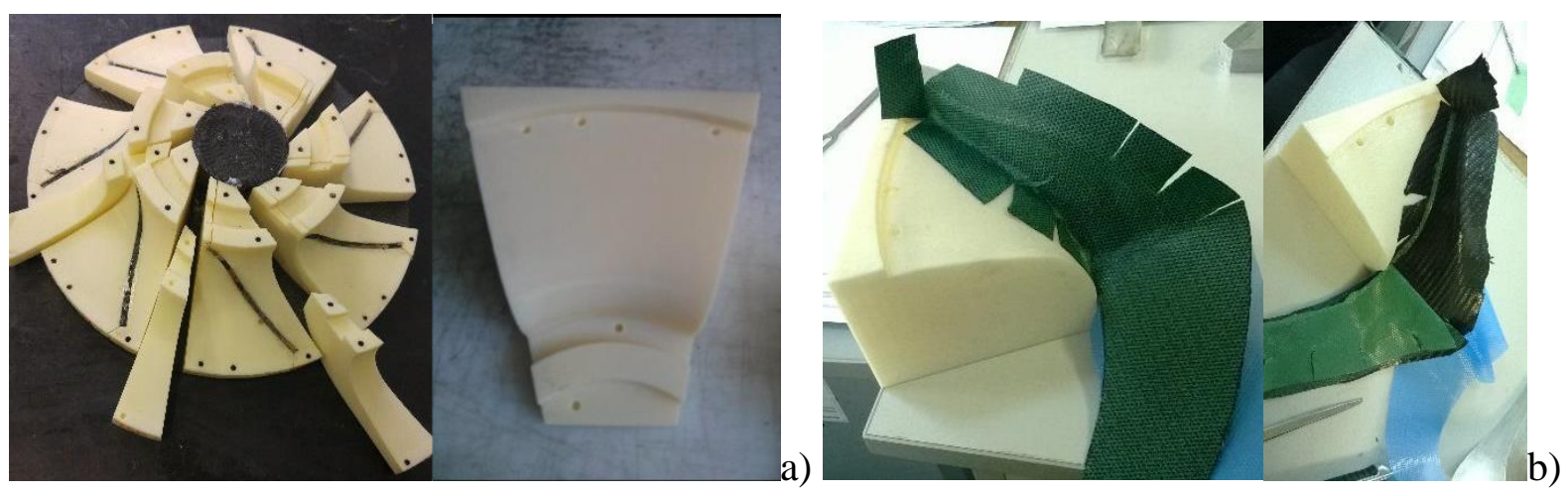

Figure 10. a) 3D printed ABS mould parts for mould assembly;

b) manufacturing stage of a composite impeller blade

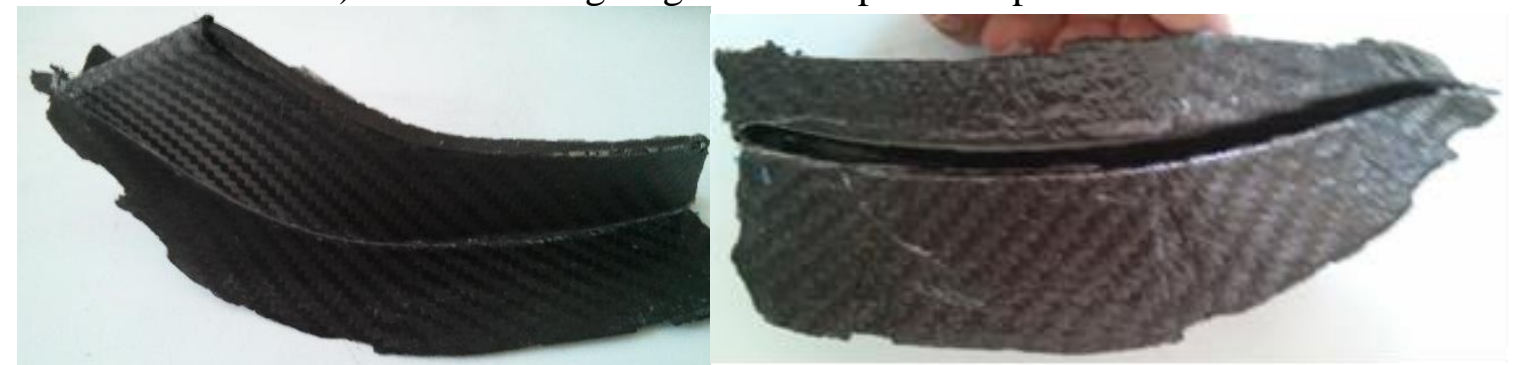

Figure 11. Final composite blade manufactured using 3D printed thermoplastic material 


\section{Conclusions}

Three thermoplastic materials were investigated for the manufacturing process of a composite rotor impeller blade, as they exhibit very high dimensional stability, high compression strength, high stiffness and good machining, perfect qualities for mould fabrication. Different milling operations have been performed on all three thermoplastic materials to select the best machining regimes. The results showed that microstructure and morphology have a critical influence on materials performances. N1001 exhibits the higher performances in terms of mechanical strength, hardness, workability, surface quality but a lower working temperature while N702 has acceptable mechanical strength, hardness but high thermal resistance up to $140^{\circ} \mathrm{C}$. The scaled impeller blades presented good tolerances with respect to CAD model and high quality surface. Moreover, several thermoplastic components were 3D printed for a 1:1 scale mould to manufacture full scale composite impeller blades. This technology was also validated as moulding capability for fabrication of composite parts with high geometry complexities.

\section{Acknowledgements}

This work is supported by the project ANTREPRENORDOC, in the framework of Human Resources Development Operational Programme 2014-2020, financed from the European Social Fund under the contract number 36355/23.05.2019 HRD OP /380/6/13 - SMIS Code: 123847." The authors are grateful for all members from the INOVABIOMED project, ID: P_36_611:145/26.10.2016, http:// www.inovabiomed.upb.ro/ and the University POLITEHNICA of Bucharest for technical support. Also, the authors would like to thank the editors and anonymous reviewers.

\section{References}

1.***Prepreg Technology, Hexcel Composites, Duxford, Publication No. FGU 017, https://ethz. ch/content/dam/ethz/special-interest/mavt/design-materials-fabrication/composite-materialsdam/Education/Manufacturing_of_Polymer_Composites/FS2017/Prepreg_Technology.pdf

2. PATIL, M.S., Composite Wound Axial Turbomachinery Impeller for Green-Renewable Energy: Applications and Numerical Structural Analysis, Ph.D. Thesis, Michigan State Univesity, 2014

3. NECUMER GmbH, http://necumer.com/index.php/en-us/

4. MARSAVINA, L., CERNESCU, A., LINUL, E., SCURTU, D., CHIRITA, C., Experimental Determination and Comparison of Some Mechanical Properties of Commercial Polymers, Mater. Plast., 47, (1), 2010

5. AMARANDEI, M., VIRGA, A., BERDICH, K.N., MATTEOLI, S., CORVI, A., MARSAVINA, L., The Influence of Defects on the Mechanical Properties of some Polyurethane Materials, Mater. Plast., 50, 84-87.

6. GHITA. E., GILliCH, G., BORDEASU, Il., VODA, M., TROI, C., Aspecte ale comportarii polimerilor la solicitari de tractiune, Mater. Plast., 44, (2), 2007, 158

7. BEJ, A., BORDEASU, I., MILOS, T., BADARAU, R., Considerations Concerning the Mechanical Strength of Wind Turbine Blades Made of Fiberglass Reinforced Polyester, Mater. Plast, 49, (3), 2012, 212

8.***Besttools,https://www.btools.ro/placi-poliuretanice-necuron/produs/9-placi-poliuretanicenecuron-cu-densitate-mica/45-necuron-651

9.Besttools,https://www.btools.ro/placi-poliuretanice-necuron/produs/11-placi-necuron-dinrasiniepoxidice/54-necuron-702

10.***Besttools,https://www.btools.ro/placi-poliuretanice-necuron/produs/10-placi-poliuretanicenecuron-cu-densitate-mare/48-necuron-1001 